\title{
Dominance and Nurturance as the Two-Factor Structure of BSRI
}

\author{
Adelia de Miguel $^{*}$, Ascensión Fumero \\ Department of Personality, Evaluation and Psychological Treatment, School of Psychology. Guajara Campus,Universidad de La Laguna \\ *Corresponding author: admiguel@ull.es
}

Copyright (C) 2013 Horizon Research Publishing All rights reserved.

\begin{abstract}
The objective of this study (female $\mathrm{N}=1072$, male $\mathrm{N}=471$ ) was replication of multidimensionality of Bem Sexual-Role Inventory (BSRI; Bem, 1974) defended by Fernández and his research group in Spain. A methodological but not ideological approach is used to analyze the answers with an exploratory factor analysis.Methodological and substantive arenas will be examined. Excluding effects of social desirability and social evolution, a first selection of items provides clearly an orthogonal two-factor structure, in adult people. Reliabilities of both new re-named nurturance and dominance components are 0.80 and 0.78 , respectively. There are sex differences in both new components: women' score was higher than men score for nurturance factor, and lower for dominance factor. The results of a cross-tab analysis also indicate sex differences in fourfold typology combining both factors like Bem's median split procedure. Finally, convergent validity with personality basic tendencies and their facets recommends making a re-conceptualization of both nurturance and dominance factors like personality traits.Implications for further studies of gender identity social values in Spain are discussed from evolutionary approach.
\end{abstract}

Keywords Gender, Sex, Nurturance, Dominance, Personality Traits

\section{Introduction}

The instrument and the theory underlying to Bem Sex-Role Inventory (BSRI, Bem, 1974) have received methodological and theoretical critiques from its first publication.

The main methodological and conceptual critiques are focused on procedure used to select items, cultural definitions used and feminist reasons to valuate cultural and social influences on constructing sex-roles.

Bem (1979) explained clearly the strategy utilized in BSRI construction. In short, the sex-typed individual was conceptualized as someone who is highly attuned to cultural definitions of sex-appropriate behavior and who uses such definitions as the ideal standard against which her or his own behavior is to be judged (p. 1048).

Firstly, such culture's definitions of desirable female and male personalities for American society of 70 decade were used for undergraduate judges at Stanford University to select items from an item pool of 200 personality characteristics. Masculinity and Femininity scales emerged using this criterion:A personality characteristic was qualified as feminine if it was independently judged by both females and males to be significantly more desirable for a woman as for a man (Bem, 1981, p.19). 20 items judged to fit the definition of femininity being expressive orientation were included in the final F scale and other 20 itemsjudged to fit the definition of masculinity being instrumental orientation were included in the final M scale (Bem, 1974). Expressive orientation means affective concern for the welfare of others (Bem 1974, p.156) and instrumental orientation means cognitive focus on getting the job done (Bem, 1974, p.156).

Secondly, Bem made an item selection based on factor loadings. The number of items in each subscale was reduced to half of the original BSRI. The short form was published in 1981. Masculinity and Femininity were two independent dimensions.

Sex-differences in both original and new scales suggested that BSRI be scored on the basis of a median-split on both dimensions, yielding four distinct groups of individuals (masculine, feminine, androgynous, and undifferentiated).

However, PedhazurandTetenbaum (1979) suggested BSRI did not assess two orthogonal scales but four dependent factors using factor analyses. Similar results have been found by FernándezandCoello (2010), and Fernández, Quiroga, delOlmo, and Rodríguez (2007) in Spain.

Four main questionswould have to be discussed in both Spanish studies. The first one, factorial validity in both Fernández's studies is located in first order structures. Neither both papers indicated first order correlations, nor did ever calculate a second order factor analysis.

The second one, items used by FernándezandCoello (2010) are much selected: Two six-item scales for masculinity and femininity, obtained by Mateo \&Fernández (1991) with 
BSRI with university students.

The third one, the sample used by Fernándezet al., (2007) consisted of university students, and Fernándezand Coello (2010)'s samplewas teenagers, 12-15 years old. People are constructing their self-concept in that stage: they select behaviors and attributes that enhance the social and cultural rewarded image, and avoid behaviors and attributes that violate that positive image. Therefore, infancy and adolescence are not adequate stages to study consolidate role-typed traits.

Choi and Fuqua (2003) published a meta-analysis using 23 journal exploratory articles, from 1974 until 1992, reportingfactor pattern coefficients on BSRI. The main conclusions of their study were: samples ranged undergraduate, graduate and noncollege adolescents, adults and senior center members; the structure of sex role orientations differs significantly across age groups; the extraction method -principal component and principal axis analysis- did not contributed to the nature of factors extracted; number of factors retained ranged from 2 to 11 , but the most frequently recurring factors were $1 \mathrm{~F}$ factor, and $2 \mathrm{M}$ factors; and factors' name were different although the items loaded on the $F$ and $M$ factor were almost identical.Choi and Fuqua (2003) concluded (...) that methodological differences and how the factor analyses were performed appear to have made little difference in the reported results, butbecause of responses from college students were used to construct BSRI little reason to expect that structures of these constructs are stable across different groups and (...) sex role orientation may require different structural definitions as one moves from one group to another (Choi \& Fuqua, 2002, p. 883).

In order to try to save these disadvantages,our first aim in the present study was to look for a two-dimension structure, selecting a sample that included university students, workers, and housewives, with a greater rank of age.

The last issue on Fernández'sis related with the authors' theoretical point of view. Fernández was working on establishing two ways to analyze individual differences between men and women, genderology and sexology, considering a priorithat gender is multidimensional but not bidimensional. So, models and names like masculinity and femininity (Bem, 1979), instrumentality and expressiveness (Spence \& Buckner, 2000; Spence \&Helmreich, 1978), and agency and communion (Lubinski, Tellegen, \&Buther, 1983), are rejected like two orthogonal one-dimensional sex-role factors. Exactly The common denominator behind these concepts is rooted in considering family, or any small group of people in general, as an entity in which dual-leadership is wielded (fathers/mothers; men/women): One leader, the father/man, tries to ensure the family adequately and efficiently fulfills concrete societal objectives (external objectives of execution) and another, the mother/women, worries about the cohesion of and positive relationships within this small group of people (Fernández\&Coello, 2010, p. 1001).

However, from evolutionary psychology, men and women are psychological different because male and female human beings must solve different adaptative problems during the last thousand years (Buss, 2008). Some of these psychological differences are related with their roles as mothers and fathers, nurture and dominance personality characteristics.

Before being mother or father, individuals must select a mate, being elected for a mate, and retained her or his mate. Mate preferences are very affected by cultural values in USA (Buss, Shackelford,Kirkpatrick, \& Larsen, 2001), China (Chang, Wang, Shackelford, \& Buss, 2011) and Spain (de Miguel, Fumero, González-Gutiérrez, \& Bello, 2010b). Personality traits, like basic tendencies of big-five model, moderate retention tactics (de Miguel, 2008; de Miguel \& Buss, 2011; de Miguel, Fumero, Bello, and González-Gutierrez, 2010a) and mate preferences (de Miguel et al. 2010b).

Sex differences in personality traits are a topic since personality psychology emerged as a psychological scientific discipline. But researchers' ideological values have an important effect on interpretation of these differences (de Miguel, 2005; de Miguel \& Fumero, 2006; Feingold, 1994; Hyde, 2005).

Masculinity and femininity roles in 1970s could be reflecting necessary and desirable personality traits, like Bem's primary assumption. Our second aim is to analyze if $\mathrm{M}$ and $\mathrm{F}$ scales converge with big five factors.

\section{Method}

\subsection{Participants}

The sample consisted of 1072 women $(\mathrm{M}$ age $=23.4, \mathrm{SD}=$ 7.6) and 471 men $(\mathrm{M}$ age $=24.9, \mathrm{SD}=8.5)$, recruited from universityand students related. There was sex difference in age $(\mathrm{t}=-3.35, \mathrm{p}=.001)$. Participation was voluntary.

\subsection{Instruments}

The Bem Sex-Role Inventory (BSRI; Bem, 1974) consists of three 20-item scales -Masculinity, Femininity, and Social Desirability. The instruction was Rate yourself on each item, on a scale from 1 (never or almost never true) to 7 (almost always true). Data analyzed correspond only to both sex-type scales.

The NEO-PI-R (Costa \& McCrae, 1992) is a self-rating questionnaire. A five-point Likert-type is used to answer 240 items, ranging from strongly agree (4) to strongly disagree (0). This instrument measures five personality basic tendencies and 30 subscales termed facets (six for each basic tendency).

\subsection{Procedure}

Subjects were administered a test battery including BSRI and NEO-PI-R. They were given as much time as they 
needed to complete the questionnaires. In order to eliminate bias in responses, subjects were asked to have sincerity because they could have their personality profile if they wanted it.

\section{Results}

A first selection of BSRI Masculinity and Femininity scales was made using a principal component analysis (PCA), oblimin rotation, and $\mathrm{n}$-factors $=2$. The two-factor structure explained $27.04 \%$ of the variance. A total of seven items were removed because contributed to both factors (defends own beliefs, assertive, self-sufficient, masculine, and willing to take a stand items from $\mathrm{M}$ scale; and cheerful, and sympathetic from $\mathrm{F}$ scale), and six others because they did not meet a minimum criteria of having a factor loading of 3 (flatterable, loyal, gullible, childlike, and does not use harsh language items form $\mathrm{F}$ scale; and individualistic item from M scale).

The remaining 14 items from $\mathrm{M}$ scale and 13 items from $\mathrm{F}$ scale were used for other PCA. The Kaiser-Meyer-Olkin measure of sampling adequacy was .86, above the recommended value of .6 , and Bartlett's test of sphericity was significant $\left(\chi^{2}=11086.8, p<.000\right)$. There was no difference between varimax and oblimin two-factor solutions. Table 1 shows the oblimintwo-factor solution..

Table 1. Structure Matrix, using Principal Component Analysis, oblimin rotation with Kaiser Normalization

\begin{tabular}{|c|c|c|c|c|}
\hline Scale & & 1 & 2 & $\mathbf{h}^{2}$ \\
\hline $\mathbf{F}$ & Tender &, 80 &, 09 & ,64 \\
\hline $\mathbf{F}$ & Gentle & ,76 &, 07 &, 58 \\
\hline $\mathbf{F}$ & Affectionate &, 71 &, 11 &, 50 \\
\hline $\mathbf{F}$ & Warm & ,70 &, 21 &, 51 \\
\hline $\mathbf{F}$ & Sensitivetoother'sneeds & ,60 &, 09 & ,36 \\
\hline $\mathbf{F}$ & Understanding &, 58 &, 15 & ,35 \\
\hline $\mathbf{F}$ & Compassionate &, 57 &, 07 &, 32 \\
\hline $\mathbf{F}$ & Loveschildren &, 53 &, 02 &, 28 \\
\hline $\mathbf{F}$ & Eager to soothe hurt feelings & 50 &, 09 &, 25 \\
\hline $\mathbf{F}$ & Yielding &, 43 &, 02 &, 19 \\
\hline $\mathbf{F}$ & Feminine & 39 &,- 23 &, 22 \\
\hline $\mathbf{F}$ & Softspoken & ,39 &, 01 &, 15 \\
\hline M & Leadershipability &, 02 &, 77 & ,60 \\
\hline $\mathbf{M}$ & Acts as a leader &,- 05 &, 76 &, 59 \\
\hline $\mathbf{M}$ & Dominant &,- 07 &, 64 &, 43 \\
\hline $\mathbf{M}$ & Competitive &,- 02 & ,61 &, 38 \\
\hline $\mathbf{M}$ & Ambitious &,- 03 &, 57 &, 33 \\
\hline $\mathbf{M}$ & Selfreliant &, 13 &, 55 &, 31 \\
\hline $\mathbf{M}$ & Strongpersonality &, 15 &, 52 & ,28 \\
\hline $\mathbf{M}$ & Willingtotakerisks &, 22 &, 52 &, 30 \\
\hline $\mathbf{M}$ & Forceful &, 25 &, 50 &, 29 \\
\hline $\mathbf{M}$ & Makesdecisionseasily &, 13 &, 46 &, 22 \\
\hline $\mathbf{M}$ & Independent &, 16 & 41 &, 18 \\
\hline $\mathbf{M}$ & Athletic &, 01 &, 38 &, 15 \\
\hline $\mathbf{M}$ & Aggressive &,- 17 & 37 &, 18 \\
\hline $\mathbf{F}$ & Shy &, 03 &,- 36 & .13 \\
\hline \multirow[t]{3}{*}{$\mathbf{M}$} & Analytical &, 18 &, 30 & .11 \\
\hline & $\%$ variance & 18.23 & 14.16 & \\
\hline & Eigenvalues & 4.92 & 3.90 & \\
\hline
\end{tabular}


The first factor explained $18.23 \%$ of the variance, and the second factor $14.16 \%$ of the variance. 12 out of $13 \mathrm{~F}$ scale items had positive factor loadings (ratio .39 - .80). The factor name proposed was nurturance. The second factor, nameddominance, consisted by all of $14 \mathrm{M}$ scale items and shyitems (negative loading) from F scale (ratio |.30 - .77|).

Internal consistency for each of the two components was examined using Cronbach's alpha. Lower alpha was .75 for dominance component by female students and higher alpha was .82 for nurturance component by female non-students (see Table 2).

Correlation between both components was .09 . Therefore, any second factor analysis was needed because they were two one-dimensional, independent dimensions.

The third analysis was focused in gender differences in both nurturance and dominance factors. Scores averages were calculated using these equations: $\left(\sum\right.$ items/12) for nurturance factor, and $\left(\sum\right.$ items $\left./ 15\right)$ for dominance factor. Both dimensions scores for men and women (total sample and by subsample) are reported in Table 3. In all three t-test, female group score was higher than male group for nurturance factor, and lower for dominance factor. However, there are no differences in both factors between students and non-students for both female and male gender.

Table 2. Cronbach' $\alpha$ Reliability by subsample and gender

\begin{tabular}{|c|c|c|c|c|c|c|c|c|c|c|}
\hline & \multicolumn{3}{|c|}{ Total sample } & \multicolumn{3}{c|}{ Students } & \multicolumn{3}{c|}{ Not-students } \\
\cline { 2 - 12 } & Total & Female & Male & Total & Female & Male & Total & Female & Male \\
\hline Nurturance & 0.80 & .81 & .81 & .80 & .80 & .80 & .81 & .82 & .80 \\
\hline Dominance & 0.78 & .76 & .79 & .77 & .75 & .77 & .79 & .77 & .81 \\
\hline
\end{tabular}

Table 3. t-test using average score ( $\sum$ items/ 12 for nurturance, and $\sum$ items $/ 15$ for dominance)

\begin{tabular}{|c|c|c|c|c|}
\hline & \multicolumn{3}{|c|}{ Mean (SD) } & \multirow{2}{*}{$\frac{\mathrm{t}}{\text { Students vs. not-students }}$} \\
\hline & Total sample & Students & Not-students & \\
\hline \multicolumn{5}{|c|}{ Nurturance } \\
\hline Female & $5.22(.74)$ & $5.23(.71)$ & $5.13(.82)$ & $\mathrm{t}=1.39$ \\
\hline \multirow[t]{2}{*}{ Male } & $4.60(.77)$ & $4.61(.76)$ & $4.55(.74)$ & $\mathrm{t}=0.68$ \\
\hline & $\mathrm{t}=15.32 * * *$ & $\mathrm{t}=13.65^{* * *}$ & $\mathrm{t}=5.29^{* * *}$ & \\
\hline \multicolumn{5}{|c|}{ Dominance } \\
\hline Female & $4.06(.72)$ & $4.08(.71)$ & $3.96(.76)$ & $\mathrm{t}=1.85$ \\
\hline \multirow[t]{2}{*}{ Male } & $4.42(.80)$ & $4.46(.76)$ & $4.32(.81)$ & $\mathrm{t}=1.56$ \\
\hline & $\mathrm{t}=-8.54^{* * *}$ & $\mathrm{t}=-8.65 * * *$ & $\mathrm{t}=-3.37 * * *$ & \\
\hline
\end{tabular}

$* * * \mathrm{p} \leq .001$

Participants were classified according to four-typology using median score in nurturance and dominance factors (direct scores but not average scores were used). Participants with scores lower than median for both factors, would be considered undifferentiated; participants with scores greater than or equal median for both factors, would be considered androgynous; participants with scores greater than or equal to the mean for nurturance factor and below the mean for dominance, would be considered as nurturance; and participants with scores greater than or equal to the mean for dominance factor and below the mean for nurturance, would be considered as dominance. Classification data are reported in Table 4. Four more important percentages need to be focused: in female group, (a) $32.7 \%$ are classified like androgynous and (b) similar percentages for nurturance and undifferentiated; in male group, (c) higher percentages are for dominance (41.7) and undifferentiated (33.0); and (d) very low percentages for nurturance and androgynous groups.

Table 4. Classification of the new fourfold typology by gender: frequencies(percentages)

\begin{tabular}{|c|c|c|c|c|c|}
\hline \multirow[b]{2}{*}{ Gender } & \multicolumn{4}{|c|}{ Four-newtypology } & \multirow[b]{2}{*}{ Total } \\
\hline & Nurturance & Dominance & Androgynous & Undifferentiated & \\
\hline Female & $292(27.2)$ & $131(12.2)$ & $350(32.7)$ & 299 (27.9) & $1072(100 \%)$ \\
\hline Male & $28(6.0)$ & $196(41.7)$ & $91(19.3)$ & $156(33.0)$ & $471(100 \%)$ \\
\hline
\end{tabular}

Finally, in order to assess convergent validity among nurturance-dominance and personality traits, six regression analyses were made for each of the new BSRI independent factors (see Table 5). This permitted the simultaneous analysis of the unique effects of age and gender (female $=0$; male $=1$ ), basic tendencies, and personality facets on both nurturance and dominance factors. 
Table 5. Regressions using age, gender and basic tendencies of personality and their facets

\begin{tabular}{|c|c|c|c|c|c|c|}
\hline & & \multirow[b]{3}{*}{$\alpha$} & \multicolumn{4}{|c|}{ Regression } \\
\hline & & & \multicolumn{2}{|c|}{ Nurturance } & \\
\hline & & & $\mathrm{R}^{2}$ & $\mathrm{p}$ & $\mathrm{R}^{2}$ & $\frac{\text { inance }}{P}$ \\
\hline & Demographics Variables & & .13 & & .05 & \\
\hline & Age & & & -.00 & & -.05 \\
\hline & $\operatorname{Sex}($ female $=0$, male $=1)$ & & & $-.36^{* * *}$ & & $.22 * * *$ \\
\hline & Basic Tendencies & & .30 & & .45 & \\
\hline & Neuroticism & .91 & & $.19 * * *$ & & $-.18^{* * *}$ \\
\hline & Extroversion & .86 & & $.27 * * *$ & & $.39 * * *$ \\
\hline & Openness & .86 & & $.13 * * *$ & & $.09 * * *$ \\
\hline & Agreeableness & .84 & & $.34^{* * *}$ & & $-.39 * * *$ \\
\hline & Conscientiousness & .90 & & $.23 * * *$ & & $.21 * * *$ \\
\hline & Facets & & .40 & & .57 & \\
\hline \multirow{6}{*}{ 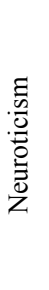 } & Anxiety & .72 & & .02 & & $-.10^{* * *}$ \\
\hline & Angry Hostility & .68 & & -.07 & & $.08 * *$ \\
\hline & Depression & .82 & & .04 & & -.01 \\
\hline & Self-Consciousness & .69 & & .07 & & -.01 \\
\hline & Impulsiveness & .57 & & .01 & & .03 \\
\hline & Vulnerability & .74 & & $.11^{* * *}$ & & $-.14^{* * *}$ \\
\hline \multirow{6}{*}{ 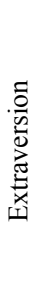 } & Warmth & .70 & & $.11 * * *$ & & .03 \\
\hline & Gregariousness & .76 & & .03 & & -.06 \\
\hline & Assertiveness & .70 & & .02 & & $.30^{* * *}$ \\
\hline & Activity & .67 & & -.05 & & $.14^{* * *}$ \\
\hline & Excitement-Seeking & .56 & & -.05 & & $.11^{* * *}$ \\
\hline & Positive Emotions & .70 & & $.19 * * *$ & & -.01 \\
\hline \multirow{6}{*}{ 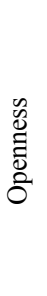 } & Fantasy & .74 & & -.03 & & -.02 \\
\hline & Aesthetics & .76 & & $.13^{* * *}$ & & -.04 \\
\hline & Feelings & .62 & & $.14^{* * *}$ & & .05 \\
\hline & Actions & .49 & & .04 & & .00 \\
\hline & Ideas & .80 & & $-.08 * *$ & & 05 \\
\hline & Values & .45 & & -.04 & & .03 \\
\hline \multirow{6}{*}{ 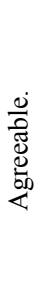 } & Trust & .72 & & -.05 & & .00 \\
\hline & Straitght-forwardness & .69 & & .02 & & $-.08 * *$ \\
\hline & Altruism & .66 & & $.21 * * *$ & & -.03 \\
\hline & Compliance & .58 & & .06 & & $-.09 * * *$ \\
\hline & Modesty & .71 & & -.03 & & $-.06^{* *}$ \\
\hline & Tender-Mindedness & .36 & & $.15^{* * *}$ & & .01 \\
\hline \multirow{6}{*}{ 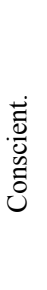 } & Competence & .64 & & .00 & & $.10^{* * *}$ \\
\hline & Order & .68 & & .05 & & .05 \\
\hline & Dutifulness & .58 & & .05 & & .03 \\
\hline & Achievement Striving & .73 & & .06 & & $.12 * * *$ \\
\hline & Self-Discipline & .79 & & .08 & & -.04 \\
\hline & Deliberation & .76 & & .01 & & -.06 \\
\hline
\end{tabular}

$* * \mathrm{p}<.01 ; * * * \mathrm{p} \leq .001$ 
The largest sex differencesare supported. Women more than men score in nurturance factor (beta $=-.36, \mathrm{p}>.001)$. Men more than women score in dominance factor $($ beta $=.22$, $\mathrm{p}>.001)$. However, age was not associated with thetwo factors.

In basic tendencies, $\mathrm{R}^{2}$ was .30 for nurturance factor and .45 for dominance factor. Extroversion, and Conscientiousness were positively associated with both factors. Agreeableness and Neuroticism were negatively associated with Dominance factor and positively associated with Nurturance factor. Higher betas were for Agreeableness and Extroversion, and lower betas for Openness.

Personality facets provide highest betas $(.40$ for nurturance and .57 for dominance).Not all the facets in each basic tendency have important relationships (higher than .09).

Neuroticism facets had the opposite profile. Nurturance was positively associated with vulnerability; Dominance was negatively associated with anxiety and vulnerability.

Positive relationships with Extroversion facets were specific for BSRI factors. Warmth and positive emotions were only with nurturance; and assertiveness, activity and excitement-seeking, only with dominance.

Two openness facets were associated with nurturance factor (aesthetics and feelings) and none with dominance factor. Altruism and tender-mindedness, as agreeableness facets, were associated only with nurturance factor. And the conscientiousness facets competence and achievement striving were positively associated with dominance factor.

\section{Discussion and Conclusion}

Traditional sexual-gender roles conceptualization needs a change, but it depends on researcher theoretical and ideological points of view. The hypothesis that gender is socially generated and is not similar to sex, is receiving a growing support but may be biased from empirical and theoretical studies.

The results from the current study refuse the hypothesis of multidimensionality as opposed to bi-dimensionality (Fernández\&Coello, 2010; Fernández et al., 2007) and clearly support bi-dimensionality in BSRI (Bem, 1974, 1979). Furthermore, content analysis explains a necessary selection of items; discriminant validity provides light to social change in gender-sexual values in Spain; and multiple regression analyses of predictors of new BSRI factors support a different conceptualization of both nurturance and dominance factors. Both factors could be proposed as personality traits.

More specifically, first, in our study the sample selection could be more adequate because age range is higher and more professionals than students are included. It is not representative of population, but it is near to Choi \& Fuqua (2003) recommendation.

Second, previous selection of items before making factor analysis removed characteristics inadequate to contemporary cultural values. Defending own beliefs, assertive, and self-sufficient from $\mathrm{M}$ scale are positive and desirable traits for men and women in century XXI. They were removed because they loaded in previous factors. Pedhazur\&Tetenbaum (1979) suggested gullible and childlike items may have been misassigned to $\mathrm{F}$ scale and comprised a factor reflecting emotional immaturity. We think these traits just show social undesirability.Both gullible and childlike items were removed to make factor analysis in this work, because neither contributed to previous factor structure. Probably, this is consequence of social change experimented by women more than men, like Franz \& McClelland (1994) reported.

Third, KMO index was adequate (Kaiser, 1960). Using nfactors $=2$ like criterion for factor solution with oblimin rotation guarantee dependent relation -if there is- between factors. However, both factors were orthogonal, and had reliabilities higher to 0.70 established index (Nunnally\& Bernstein, 1994).

Fourth, short form F scale (Bem, 1981) consisted by tender, gentle, affectionate, warm, sensitive to other's needs, understanding, compassionate, loves children, eager to soothe hurt feelings, and sympathetic. These 10 items were the most frequently and significantly loaded in Choi \& Fuqua (2003)'s. All of them, except sympathetic, were retained in the nurturance factor in the present study.

Dominance factor consists by 8 of 10 items M scale from short form of BSRI (Bem, 1981): leadership ability, dominant, self-reliant, strong personality, willing to take risks, forceful, independent, and aggressive. Assertive and to take and stand were removed in this study. This factor was founded in other studies but in other ones two factors were needed to explain M scale (Choi \& Fuqua, 2003.

In short, structurally, nurturance factor is similar to the expressiveness or communal original and contrasted $\mathrm{F}$ scale. Also, dominance factor is similar to the agentic and instrumental original $\mathrm{M}$ scale.

Fifth, contrary to generology point of view of Fernández (2010), dominance and nurturance factors could be reflected an interdependence of evolutionary and cultural reasons. Male group self-rate higher than female group in dominance factor, but lower in nurturance factor. The robustness of these sex differences support to the main original hypothesis of Bem's gender roles. In addition,female group is classified in new fourfold typology in three groups (nurturance, androgynous and undifferentiated) meanwhilemale group only needs two types (dominance and undifferentiated). Women appear to be adaptating to changes in cultural and social values in Spain, which are promoting an extensive and relativist framework. This environmentdoes not help children to generate a self-image using rigid gender and sex rules, above all in men.

And sixth, relationships with basic tendencies and facets of personality reply dominance and nurturance like personality traits. Dominance is predicted by emotional stability and non-agreeableness. Nurturance is predicted by emotional instability and agreeableness. These results are 
similar to Marušic\&Bratko(1998) study, and are consistent with evolutionary premises. Dominance is needed to protect family for external threats, being adequate emotional stability and aggressive behaviors. Nurturance is needed to provide care to children, being adaptative emotional instability and agreeableness.

This study relied exclusively on the use of self-reports to assess sex-roles and personality traits. Costa, Terracciano\& McCrae (2001) informed this mono-method approach is responsible of many of the difficulties in interpreting cultural differences in gender differentiation on personality traits. Choi, Fuqua, \& Newman (2008) reported of different factor-structures for BSRI using self-ratings, desirability ratings for a man, and desirability ratings for a woman.

\section{REFERENCES}

[1] Bem, S.L. (1974). The measurement of psychological androgyny. Journal of Consulting and Clinical Psychology, 42, 155-162.

[2] Bem, S.L. (1979). Theory and measurement of androgyny: A reply to the Pedhazur-Tetenbaum and Locksley-Colten critiques. Journal of Personality and Social Psychology, 37, 1047-1054.

[3] Bem, S.L. (1981). A manual for the Bem Sex-Role Inventory. Palo Alto, CA: Consulting Psychological Press.

[4] Budaev, S.V. (1999). Sex differences in the Big Five personality factors: Testing an evolutionary hypothesis. Personality and Individual Differences, 26, 801-813.

[5] Buss, D. M. (2008). Evolutionary psychology: The new science of the mind (3rd ed.).Boston, MA: Allyn\& Bacon.

[6] De Miguel, A. y Buss, D.M. (2011). Mate Retention Tactics in Spain: Personality, Sex Differences, and Relationship Status. Journal of Personality.http://onlinelibrary.wiley.com/doi/10.1111/j.146 7-6494.2011.00698.x/abstract.

[7] Buss, D. M., Shackelford, T. K., Kirkpatrick, L. A., \& Larsen, R. J. (2001). A half centuryof American mate preferences: The cultural evolution of values. Journal of Marriageand the Family, 63, 491-503.

[8] Chang, L., Wang, Y., Shackelford, T.K., \& Buss, D.M. (2011). Cultural evolution andcultural continuity across a quarter of a century: An illustration using Chinese mate preferences. Personality and Individual Differences, 50, 678-683.

[9] Choi, N. \&Fuqua, D.R. (2003). The structure of the Bem Sex-Role Inventory: A summary report of 23 validation studies. Educational and Psychological Measurement, 63 (5), 872-887.

[10] Choi, N., Fuqua, D.R. \& Newman, J.L. (2008). The Bem Sex-Role Inventory. Continuing Theoretical Problems. Educational and Psychological Measurement, 68(5), 881-900.

[11] Costa, P.T. \&McCrae, R.R. (1992). NEO PI-R, Revised Neo
Personality Inventory and NEO Five-Factor Inventory (NEO-FFI). PAR Psychological Assessment Resources. IncOdessa. Florida (Spanish adaptation, 1999, TEAEdiciones, S.A.)

[12] Costa, P.T., Terracciano, A., \&McCrae, R.R. (2001). Gender differences in personality traits across cultures: robust and surprising findings. Journal of Personality and Social Psychology, 81(2), 322-331.

[13] de Miguel, A. (2005). Diferencias de edad y género en el NEO-PI-R en dos muestras con distinto nivel académico. International Journal of Psychology and Psychological Therapy, 5(1), 13-31.

[14] de Miguel, A (2008). Tácticas de retención de lapareja: efectosdel sexo y la edad. Relaciones conpersonalidad. $X$ Jornadas de SEIDI, Salamanca.

[15] de Miguel, A. y Fumero, A.(2006). A vueltas con las diferencias de género en el NEO-PI-R.VIII Reunión de la SEIDI, Enero, Madrid.

[16] De Miguel, A., Fumero, A., Bello, M.y González-Gutiérrez, J.A. (2010a). Estrategias de retención de pareja en personas homosexuales y heterosexuales. XII Jornada SEIDI, Málaga

[17] De Miguel, A., Fumero, A., González-Gutiérrez, J.A. y Bello, M. (2010b). Preferencias de pareja en personas homosexuales y heterosexuales. XII Jornada SEIDI, Málaga.

[18] Feingold, A. (1994). Gender differences in personality: A meta-analysis. Psychological Bulletin, 116, 429-456.

[19] Fernández, J. \& Coello, M. T. (2010). Do the BSRI and PAQ really measure masculinity and femininity? The Spanish Journal of Psychology, 13, 1000-1009.

[20] Fernández, J., Quiroga, M.A., del Olmo, I. \& Rodríguez, A. (2007). Escalas de masculinidad y feminidad: estado actual de la cuestión. Psicothema, 19, 357-365.

[21] Franz, C.L. \&McClelland, D.C. (1994). Lives of women and men active in the social protests of the 1960s: a longitudinal study. Journal of Personality and Social Psychology, 66(1), 196-205.

[22] Hyde, J.S. (2005). The Gender Similarities Hipothesis. American Psychologist, 60(6), 581-592.

[23] Kaiser, H. F. (1960). The application of electronic computers to factor analysis. Educational and Psychological Measurement, 20, 141-151.

[24] Lubinski, D., Tellegen, A. \& Butcher, J.N. (1983). Masculinity, femininity, and androgyny viewed and assessed as distinct concepts. Journal of Personality and Social Psychology, 44, 428-439.

[25] Mateo, M.A. \& Fernández, J. (1991). La dimensionalidad de los conceptos de masculinidad y feminidad. InvestigacionesPsicológicas, 9, 95-116.

[26] Marušic, I. \&Bratko, D. (1998). Relations of masculinity and femininity with personality dimensions of the five-factor model. Sex Roles, 38(1/2), 29-44.

[27] Nunnaly, J.C. \& Bernstein, I.H. (1994). Psychometric theory ( $3^{a}$ ed.), New York, NY: McGraw-Hill.

[28] Pedhazur, E.J. \&Tetenbaum, T.J. (1979). Bem Sex Role Inventory: A theoretical and methodological critique. Journal 
of Personality and Social Psychology, 37, 996-1016.

[29] Spence, J.T. (1983). Comment on Lubinski, Tellegen, and Butcher's "Masculinity, femininity, and androgyny viewed and assessed as distinct concepts". Journal of Personality and
Social Psychology, 44, 440-446.

[30] Spence, J.Y. \&Helmreich, R.L. (1978). Masculinity and femininity: Their psychological dimensions, correlates and antecedents. Austin: University of Texas Press. 